\begin{tabular}{l} 
KONSTAN \\
JURNAL FISIKA DAN PENDIDIKAN FISIKA \\
$\begin{array}{r}\text { Volume 6, Nomor 2, Desember 2021 } \\
\text { E-ISSN : 2460-9129 dan P-ISSN : 2460-9110 } \\
\text { http://jurnalkonstan.ac.id/index.php/jurnal }\end{array}$ \\
\hline
\end{tabular}

\title{
Pemahaman Konsep Fluida Statis dengan Contrasting Cases
}

\author{
Rima Buana Prahastiwi ${ }^{1, *)}$, Arif Hidayat ${ }^{2}$, Eny Sulasmi ${ }^{3}$ \\ 1) Tadris Fisika, Fakultas Tarbiyah dan Keguruan, Universitas Islam Negeri Mataram, Jln. Gajah Mada 100, \\ Jempong Baru, Mataram, Indonesia \\ 2) Fisika, Fakultas Matematika dan Ilmu Pengetabuan Alam, Universitas Negeri Malang, Jln. Semarang 5, \\ Malang, Malang, Indonesia \\ ${ }^{3)}$ Fisika, Sekolah Menengah Atas Negeri 8 Kediri, Jln. Pablawan Kusuma Bangsa 77, Kediri, Kediri, Indonesia \\ *E-mail korespondensi: rimabuana@uinmataram.ac.id
}

\begin{abstract}
Info Artikel: Abstract
Dikirim:

26 Januari 2022

Revisi:

04 Maret 2022

Diterima:

05 Maret 2022

Kata Kunci:

Contrasting cases, fluida statis, pemahaman konsep

Penelitian ini bertujuan untuk mengetahui bagaimana proses pembelajaran dengan contrasting cases dan peningkatan pemahaman konsep siswa pada materi fluida statis setelah diberikan perlakuan pembelajaran dengan contrasting cases. Penggunaan contrasting cases bertujuan untuk memudahkan siswa dalam menemuan ciri penting dari suatu konsep agar pemahaman konsep mengalami peningkatan. Mixed Method: Embedded Experimental Design merupakan metode penelitian yang digunakan dalam proses penelitian. Metode penelitian ini digunakan untuk memperoleh data proses pembelajaran dan pemahaman konsep siswa secara lengkap yang ditinjau dari sebelum perlakuan, proses yang dilakukan selama perlakuan, dan setelah perlakuan. Data diperoleh dengan melakukan observasi dan memberikan 12 soal pilihan ganda beralasan kepada 33 siswa SMA kelas XI IPA. Berdasarkan hasil penelitian diketahui proses pembelajaran dengan contrasting cases yang diamati oleh tiga observer memperoleh tingkat keberhasilan rata-rata $86,44 \%$ dari $100 \%$. Untuk hasil dari pemahaman konsep fluida statis yang ditinjau dari statistik deskriptif yaitu terjadi peningkatan rata-rata skor prepost-test 2,67 ke 5,70. Berdasarkan hasil statistik deskriptif maka dapat dilakukan uji lanjut. Uji lanjut dilakukan untuk mengetahui meningkatnya pemahaman konsep yaitu dengan menggunakan perhitungan $N$-gain yang diperoleh skor sebesar 0,32. Skor tersebut berada pada kategori sedang. Berdasarkan hasil penelitian dapat disimpulkan bahwa pembelajaran dengan contrasting cases dilakukan dengan baik dan terjadi peningkatan pemahaman konsep dengan kategori sedang. Untuk penelitian selanjutnya perlu adanya pembiasaan lebih lama dalam proses pembelajaran dengan contrasting cases agar siswa dapat dengan mudah menemukan ciri penting dari suatu konsep. Selain itu dalam melakukan pembiasaan dapat juga dikembangkan kasus yang dihadirkan dalam pembelajaran lebih terlihat kekonstrasannya dengan begitu diharapkan terjadi peningkatan pemahaman konsep yang lebih baik.
\end{abstract}

(C) 2021 Universitas Islam Negeri Mataram

\section{PENDAHULUAN}

Pemahaman konsep merupakan tema penelitian pendidikan yang terus dikembangkan. Ranah yang diteliti untuk meningkatkan pemahaman konsep sampai saat ini meliputi penilaian [1], [2], pengembangan pembelajaran yang meliputi strategi, pendekatan, model, dan metode pembelajaran [1]-[4], serta deskripsi tentang kesulitan siswa pada materi tertentu[1], [5]. Ranah penelitian tersebut mempunyai satu tujuan yang sama, yaitu meningkatknya pemahaman konsep siswa. 
Pemahaman konsep untuk materi fluida statis masih perlu ditingkatkan. Hal ini terbukti masih ada kesulitan siswa pada materi tersebut. Siswa mengalami kesulitan pada submateri tekanan hidrostatis[6], [7], Hukum Pascal[7], dan Hukum Archimedes[4], [7], [8].

Upaya yang dilakukan dalam peningkatan pemahaman konsep pada materi ini sudah banyak. Mulai dari mengembangkan media pembelajaran dengan simulasi[9], mengembangkan modul belajar[4], mengeksplor kesulitan siswa[6], dan merancang pembelajaran dengan menggunakan POE [8], pembelajaran berbasis masalah[10]. Salah satu upaya yang dilakukan pada artikel ini adalah merancang strategi pembelajaran yang aktif dan interaktif agar terjadi peningkatan pada materi fluida statis[1], [11].

Rancangan pembelajaran yang mencakup kelebihan dan dapat digunakan untuk memperbaiki kekurangan pada pembelajaran terdahulu adalah pembelajaran dengan menggunakan contrasting cases. Contrasting cases merupakan suatu pendekatan pembelajaran yang mempunyai manfaat untuk mengarahkan siswa menemukan ciri penting dari suatu konsep dan sebagai persiapan dalam pembelajaran selanjutnya[1], [11].

Dengan menggunakan contrasting cases pada pembelajaran dapat memudahkan siswa dalam memperoleh pemahaman dari suatu konsep. Berdasarkan hasil kajian dan studi literatur dari penelitian terdahulu serta permasalahan yang terjadi pada hasil observasi awal, maka peneliti melaksanakan penelitian yang bertujuan untuk mengeksplor pemahaman konsep fisika siswa pada materi fluida statis dengan pembelajaran yang dikaitkan dengan contrasting cases.

\section{Proses Pembelajaran Contrasting Cases Pada Materi Fluida Statis}

Penelitian pada fluida statis dibagi menjadi tiga submateri. Pada setiap submateri disajikan tiga sampai empat kasus yang berhubungan. Dari kasus tersebut siswa diminta untuk menentukan jawaban beserta alasannya, misalnya pada tekanan hidrostatis siswa diminta untuk menentukan tekanan hidrostatis yang terkecil, terbesar, dan sama beserta alasannya jika yang divariasi adalah kedalaman titik yang diukur. Dari kasus tersebut siswa dapat menemukan ciri penting pada tekanan hidrostatis, yaitu tekanan hidrostatis dipengaruhi oleh kedalaman yang diukur dari permukaan zat cair. Berikut contoh contrasting cases materi fluida statis pada Gambar 1.
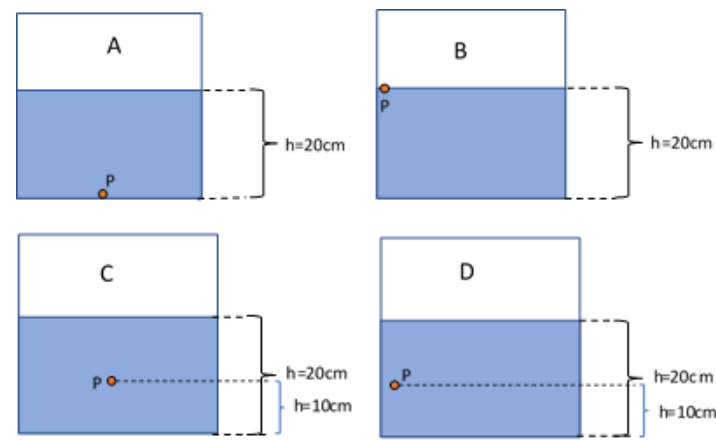

Gambar 1. Contoh Contrasting Cases pada Materi Fluida Statis

Berdasarkan Gambar 1 siswa diharapkan dapat mengidentifikasi ciri penting bahwa urutan tekanan hidrostatis dari yang terkecil sampai terbesar adalah bejana B, C=D, dan A.

\section{METODE PENELITIAN}

Mixed Method: Embedded Experimental Design adalah metode penelitian yang digunakan pada penelitian ini. Metode penelitian ini digunakan untuk memperoleh data proses pembelajaran dan pemahaman konsep siswa secara lengkap yang ditinjau dari sebelum perlakuan, proses yang dilakukan selama perlakuan, dan setelah perlakuan. Pengumpulan data proses pembelajaran dengan menggunakan lembar observasi dan data pemahaman konsep menggunakan tes dengan memberikan 
12 soal pilihan ganda beralasan. Salah satu dari Kelas XI SMA Negeri 8 Kediri pada semester genap tahun ajaran 2016/2017 digunakan sebagai subjek penelitian. Prosedur penelitian fluida statis dengan contrasting cases dapat dilihat pada Gambar 2.

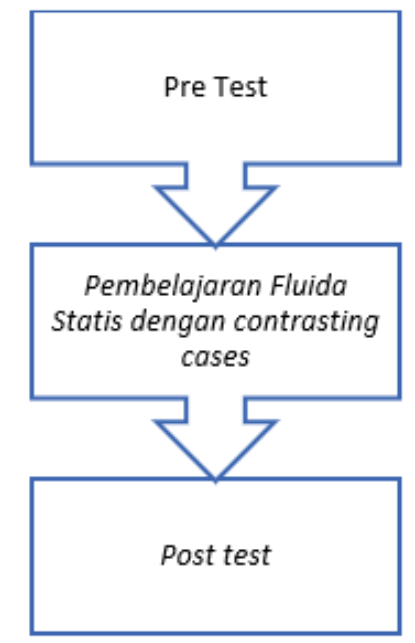

Gambar 2. Prosedur Penelitian Pembelajaran Fluida Statis dengan Contrasting Cases

Pada Gambar 2, prosedur penelitian diawali dengan pre test untuk mengetahui pemahaman konsep siswa sebelum diberi perlakuan. Setelah itu dilanjutkan dengan pembelajaran yang disisipkan contrasting cases pada LKS dengan tujuan ciri penting pada pembelajaran dapat ditemukan dengan mudah oleh siswa sehingga terjadi peningkatan pemahaman konsep pada materi fluida statis. Setelah memberikan perlakuan, tahap berikutnya adalah post test sehingga diketahui peningkatan pemahaman konsep siswa setelah pemberian perlakuan.

Untuk mengetahui peningkatan prepost-test setelah melakukan intervensi serta mengetahui peningkatan jumlah jawaban benar pada soal prepost-test[12]. Nilai N-Gain dapat ditentukan dengan menggunakan kategori sebagai berikut.

\begin{tabular}{cc} 
Tabel 1. Kategori N-Gain & \\
Gain ternormalisasi & Peningkatan \\
\hline$G<0,3$ & Rendah \\
$0,3 \leq G<7$ & Sedang \\
$G \geq 0,7$ & Tinggi \\
\hline
\end{tabular}

\section{HASIL DAN PEMBAHASAN}

Pembelajaran pada penelitian ini dilaksanakan sebanyak lima kali pertemuan. Setiap pertemuan berdurasi sembilan puluh menit dengan tahapan pembelajaran sebagai berikut stimulasi dengan menampilkan permasalahan yang terjadi di kehidupan sehari-hari, problem statement berupa penyusunan hipotesis dan pengajuan pertanyaan, data collection dilakukannya pengambilan data secara praktikum, data processing memproses data yang sudah diperoleh, verification memverifikasi atau mengecek ulang data yang sudah diperoleh, dan generalization merupakan tahap kesimpulan [13]. Pada proses pembelajaran tahap data collection disisipkan contrasting cases.

Contrasting cases adalah metode yang memberikan suatu kasus ketika pembelajaran berlangsung. Kasus yang dihadirkan adalah kasus yang berhubungan dengan materi yang dipelajari. Kasus tersebut dihadirkan agar konsep yang diajarkan dapat dengan mudah dipahami dan ditemukan oleh siswa. Pembelajaran yang dilakukan sebanyak lima pembelajaran, ada tiga sampai empat kasus yang diberikan pada setiap pembelajaran yaitu pada tahap data collection. Tujuan pemberian kasus pada data collection agar pola penting [11] serta ciri penting dari materi yang dipelajari dapat temukan dengan mudah oleh siswa [1], [11]. Cara penemuan ciri penting atau pola tersebut dilakukan secara diskusi dan berkelompok. Proses pembelajaran dengan contrasting cases dapat dilihat pada Gambar 3. 


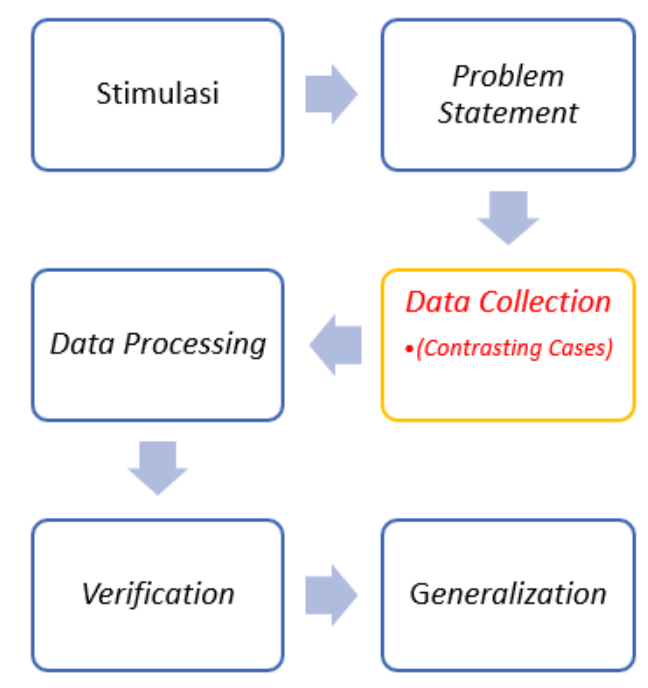

Gambar 3. Proses Pembelajaran dengan Contrasting Cases

Data selanjutnya yang diperoleh adalah data keterlaksanaan pembelajaran. Hal ini peneliti dibantu observer dalam hal melakukan observasi proses pembelajaran, berikut data keterlaksanaan pembelajaran yang dapat dilihat pada Tabel 2 .

Tabel 2. Keterlaksanaan Pembelajaran

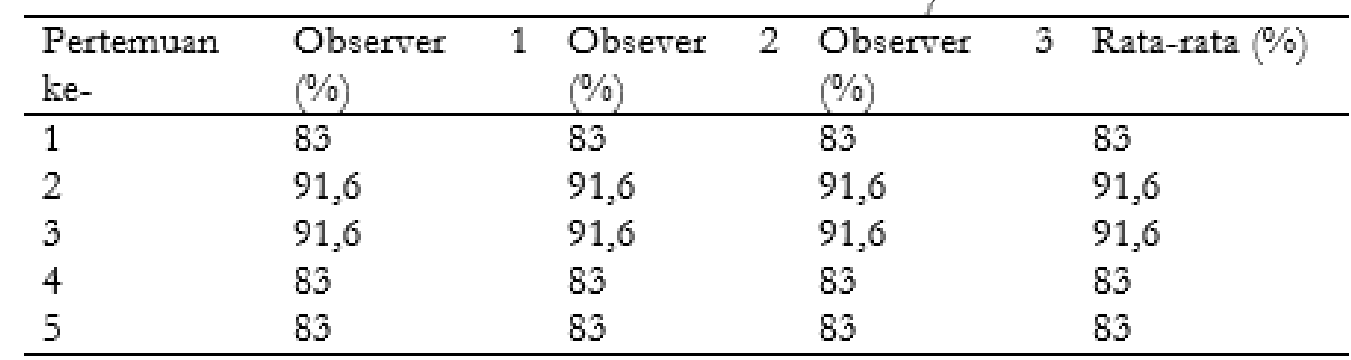

Berdasarkan Tabel 2 diketahui bahwa pembelajaran yang dilakukan belum mencapai $100 \%$. Kriteria $100 \%$ adalah ketika semua langkah pembelajaran terlaksana. Hal ini tidak terjadi karena guru kurang bisa mengatur waktu sehingga ada langkah pembelajaran yang terlewatkan yaitu pada saat pemberian contoh soal dan soal latihan. Selain itu faktor lainnya adalah siswa masih belum terbiasa melakukan praktikum sehingga waktu yang diperlukan untuk praktikum lebih lama dan mengakibatkan langkah pembelajaran berikutnya tidak bisa tercapai. Meskipun keterlaksanaan pembelajaran belum mencapai $100 \%$, dapat dilihat bahwa pertemuan ke-2 dan ke-3 terjadi peningkatan keterlaksanaan pembelajaran. Menurut catatan observer hal ini dikarenakan siswa sudah terbiasa melakukan pembelajaran seperti yang guru rancang. Jadi, langkah pembelajaran pada pertemuan ke-2 dan ke-3 yang tidak tercapai sebanyak satu tahap.

Untuk pertemuan ke-4 dan ke-5 keterlaksanaan pembelajaran turun karena siswa kebingungan dalam membaca alat ukur (gelas ukur dan neraca pegas). Guru menghabiskan waktu untuk mengajari satu per satu kelompok sehingga dua langkah pembelajaran tidak tercapai. Selain siswa kebingungan membaca alat ukur, juga dikarenakan siswa kebingungan dalam mengonversi satuan mililiter ke meter kubik sehingga siswa membutuhkan waktu sedikit lebih lama dalam pengolahan data. Oleh karena itu, pembiasaan kepada siswa perlu dilakukan agar siswa mampu mengikuti pembelajaran yang dilakukan[13].

Berdasarkan penelitian yang telah dilakukan pemahaman konsep siswa tentang materi fluida statis dengan menggunakan contrasting cases terjadi peningkatan. Jumlah jawaban siswa yang benar pada saat pre test dan post test terjadi peningkatan dengan skor $N$-gain sebesar 0,32 . Untuk submateri tekanan hidrostatis, pada pre test jumlah siswa yang menjawab dengan benar ada 23\% (7 siswa dari 33 siswa) sedangkan pada post test meningkat menjadi 53\% (17 siswa dari 33 siswa); submateri hukum pascal juga terjadi peningkatan dari 25\% (8 siswa dari 33 siswa) menjadi 40\% (13 siswa dari 33); dan submateri hukum archimedes terjadi peningkatan dari 19\% (6 siswa dari 33 siswa) menjadi 45\% (15 siswa dari 33 siswa) (Gambar 4). 


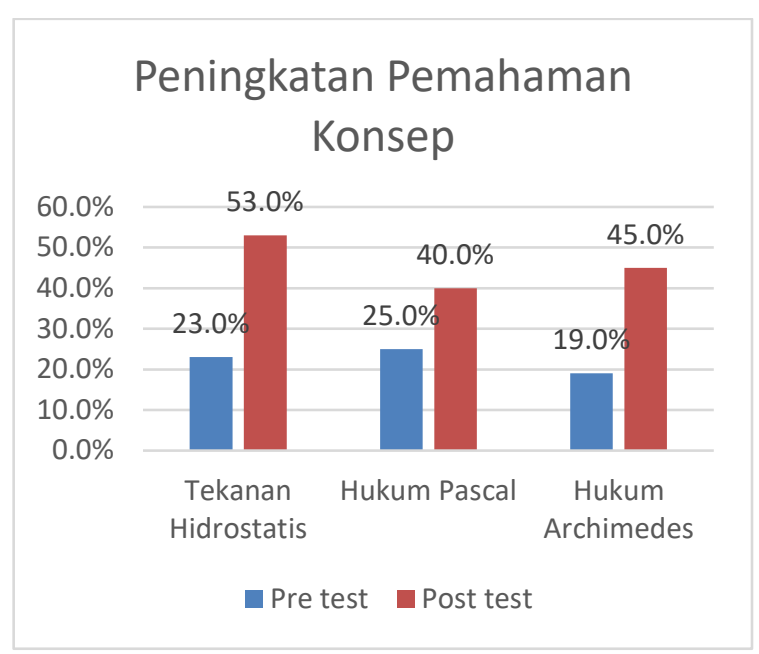

Gambar 4 . Grafik Peningkatan Pemahaman Konsep Fluida Statis

Tabel 3. Statistik Deskriptif Skor Pre-Post Test

\begin{tabular}{lll} 
& Pre Test & Post Test \\
\hline Jumlah Data (N) & 33 & 33 \\
Rata - rata & 2,67 & 5,70 \\
Standar Deviasi (SD) & 1,74 & 1,91 \\
Skor Terendah & 0 & 2 \\
Skor Tertinggi & 8 & 9 \\
Skewness & 0,81 & 0,32 \\
\hline
\end{tabular}

Dari data Tabel 3 diperoleh hasil perhitungan statistik deskriptif untuk skor pre-post test. Dapat dilihat bahwa terjadi peningkatan pada pre-post test untuk rata-rata, skor tertinggi, dan terendah. Hasil perhitungan skewness diperoleh hasil 0,81 dan 0,32 yang berarti data pre-post test terdistribusi normal, karena hasil tersebut berada pada rentang -1 sampai 1[14]. Setelah melakukan perhitungan statistik deskriptif maka dapat dilanjutkan dengan uji lanjut. Uji lanjut tersebut dapat dilihat pada Tabel 4.

Tabel 4. Uji Lanjut

\begin{tabular}{lll}
\hline Uji & Nilai & Kategori \\
\hline$t$ berpasangan & $9,18^{*}$ & $\begin{array}{l}\text { Perbedaan } \\
\text { signifikan }\end{array}$ \\
N-Gain & 0,32 & Sedang \\
Effect size & 1,59 & Kuat \\
\hline sig.(2-tailed) : 0,00 & &
\end{tabular}

Berdasarkan data Tabel 4 diperoleh hasil uji lanjut pemahaman konsep siswa. Hasil uji $t$ berpasangan sebesar 9,18 dengan signifikasi 0,00 yang berarti bahwa skor pre-post test pemahaman konsep siswa berbeda secara signifikan[14]. Hasil uji $N$-gain yang dilakukan untuk melihat peningkatan skor pre-post test pemahaman konsep siswa sebesar 0,32 dengan kategori sedang[12]. Tetapi, meskipun peningkatan pemahaman konsep siswa sedang, effect size bernilai 1,59 dengan kategori kuat yang berarti bahwa pengaruh discovery learning dengan contrasting cases terhadap pemahaman konsep siswa kuat[14]. Jadi, berdasarkan hasil uji statistik dapat disimpulkan bahwa contrasting cases dapat meningkatkan pemahaman konsep siswa.

\section{KESIMPULAN}

Dengan menggunakan pembelajaran contrasting cases, pemahaman konsep fluida statis siswa meningkat. Hal ini dikarenakan kelebihan dari contrasting cases adalah siswa dapat menemukan ciri penting dari suatu kasus. Ketika siswa sudah terbiasa untuk menemukan ciri penting dari suatu kasus maka dapat memudahkan siswa untuk menjawab soal dengan benar dari ciri penting yang sudah ditemukan tersebut, dapat membekali siswa sebagai konsep awal untuk materi selanjutnya.

Masih terdapat kesulitan yang dialami siswa pada materi fluida statis. Berdasarkan kesulitan tersebut, maka perlu adanya pengondisian siswa terkait pembelajaran yang sedikit lebih lama agar hasil peningkatan pemahaman konsep mempunyai kategori tinggi, pembagian jumlah pertemuan juga perlu 
diperhatikan, pernyataan pada soal prepost-test perlu perbaikan agar tidak memicu kesulitan siswa dalam menemukan ciri penting.

Peningkatan pada penelitian ini berada pada kategori sedang. Hal ini terjadi karena masih ada penurunan jumlah siswa yang menjawab benar pada saat post-test. Untuk meningkatkan pemahaman konsep maka perlu mengembangkan contrasting cases yang lebih terlihat kekontrasannya agar siswa dapat dengan mudah menemukan ciri penting suatu konsep. Contrasting cases dapat dikembangkan pada materi lain agar siswa terbiasa untuk menemukan ciri penting dari suatu materi serta siswa dapat memperoleh konsep awal yang matang untuk materi berikutnya.

\section{UCAPAN TERIMA KASIH}

Kami mengucapkan terima kasih kepada seluruh civitas akademi di SMA Negeri 8 Kediri. Terima kasih diucapkan untuk perijinan dalam hal pengambilan data penelitian ini.

\section{DAFTAR PUSTAKA}

[1] E. Kuo and C. E. Wieman, “Toward instructional design principles: Inducing Faraday's law with contrasting cases," Phys. Rev. Phys. Educ. Res., vol. 12, no. 1, pp. 1-14, 2016, doi: 10.1103/PhysRevPhysEducRes.12.010128.

[2] R. J. Beichner, "Testing student interpretation of kinematics graphs," Am. J. Phys., vol. 62, no. 8, pp. 750-762, 1994, doi: 10.1119/1.17449.

[3] I. S. Araujo, E. A. Veit, and M. A. Moreira, "Physics students' performance using computational modelling activities to improve kinematics graphs interpretation," Comput. Educ., vol. 50, no. 4, pp. 1128-1140, 2008, doi: 10.1016/j.compedu.2006.11.004.

[4] P. R. L. Heron, M. E. Loverude, P. S. Shaffer, and L. C. McDermott, "Helping students develop an understanding of Archimedes' principle. II. Development of research-based instructional materials," Am. J. Phys., vol. 71, no. 11, pp. 1188-1195, 2003, doi: 10.1119/1.1607337.

[5] J. L. Docktor and J. P. Mestre, "Synthesis of discipline-based education research in physics," Phys. Rev. Spec. Top. - Phys. Educ. Res., vol. 10, no. 2, pp. 1-58, 2014, doi: 10.1103/PhysRevSTPER.10.020119.

[6] M. Goszewski, A. Moyer, Z. Bazan, and D. J. Wagner, "Exploring student difficulties with pressure in a fluid," AIP Conf. Proc., vol. 1513, no. may 2012, pp. 154-157, 2013, doi: 10.1063/1.4789675.

[7] R. B. Prahastiwi, A. Hidayat, and Wartono, "Prosiding Seminar Nasional Pekan Ilmiah Fisika (PIF) XXVII Tahun 2016 UNNES,” 2016.

[8] Y. Yin, M. Tomita, and R. Shavelson, "Diagnosing and Dealing with Student Misconceptions: Floating and Sinking.," Sci. Scope, vol. 31, no. 8, pp. 34-39, 2008.

[9] J. Minogue and D. Borland, "Investigating Students' Ideas About Buoyancy and the Influence of Haptic Feedback," J. Sci. Educ. Technol., vol. 25, no. 2, pp. 187-202, 2016, doi: 10.1007/s10956-015-9585-1.

[10] I. Rahmawati, A. Hidayat, and S. Rahayu, "Peguasaan Konsep IPA Siswa SMP Pada Materi Tekanan Pada Zat Cair Dan Aplikasinya," JPS (Jurnal Pendidik. Sains), vol. 4, no. 3, pp. 102 112, 2016.

[11] D. B. Chin, M. Chi, and D. L. Schwartz, "A comparison of two methods of active learning in physics: inventing a general solution versus compare and contrast," Instr. Sci., vol. 44, no. 2, pp. 177-195, 2016, doi: 10.1007/s11251-016-9374-0.

[12] R. R. Hake, "Interactive-engagement versus traditional methods: A six-thousand-student survey of mechanics test data for introductory physics courses," Am. J. Phys., vol. 66, no. 1, pp. 64-74, 1998, doi: 10.1119/1.18809.

[13] M. T. Illahi, Pembelajaran Discovery Strategi \& Mental Vocational Skill. Jogjakarta: DIVA Press, 2012.

[14] G. A. Morgan, N. L. Leech, G. W. Gloeckner, and K. C. Barrett, SPSS for Introductory Statistics: Use and Interpretation, 2nd edition. London: Lawrence Erlbaum Associates, 2004. 